\title{
THE USE OF PROTECTIVE GLOVES BY MEDICAL PERSONNEL
}

\author{
ANNA GARUS-PAKOWSKA ${ }^{1}$, WOJCIECH SOBALA ${ }^{2}$, and FRANCISZEK SZATKO ${ }^{1}$ \\ ${ }^{1}$ Medical University of Lodz, Łódź, Poland \\ Department of Hygiene and Health Promotion, Department of Hygiene and Epidemiology \\ ${ }^{2}$ Nofer Institute of Occupational Medicine, Łódź, Poland \\ Department of Environmental Epidemiology
}

\begin{abstract}
Introduction: To minimize the risk of cross-infection between the patient and the medical staff, it is necessary to use individual protective measures such as gloves. According to the recommendations of the Centers for Disease Control and Prevention (CDC) and the World Health Organization (WHO), protective gloves should always be used upon contact with blood, mucosa, injured skin or other potentially infectious material. Materials and Methods: The aim of the study was to evaluate, through quasi-observation, the use of protective gloves by medical staff according to the guidelines issued by the CDC and WHO. The results were subject to statistical analysis $(\mathrm{p}<0.05)$. Results: During 1544 hours of observations, 3498 situations were recorded in which wearing protective gloves is demanded from the medical staff. The overall percentage of the observance of using gloves was $50 \%$. The use of gloves depended significantly on the type of ward, profession, performed activity, number of situations that require wearing gloves during the observation unit and the real workload. During the entire study, as many as 718 contacts with patients were observed in which the same gloves were used several times. Conclusion: Wearing disposable protective gloves by the medical staff is insufficient.
\end{abstract}

Key words:

Compliance with procedures, Protective gloves, Hygiene, Medical personnel

\section{INTRODUCTION}

Protective gloves are an essential factor in microbial protection, both for medical professionals and patients. According to the opinion of the CDC (Centers for Disease Control and Prevention, Atlanta), gloves are used by health professionals in order to:

- Minimize the risk of microbial transmission from patients to medical personnel,

- Protect patients against the transfer of bacterial flora from medical workers,

- Minimize the contamination of the hands of medical personnel with transient microbial flora which may be transferred from one patient to another [1].
Gloves reduce the likelihood of contamination of the hands with bacterial flora by about 70-80\% [2]. Pittet et al. showed that the skin of the hands of medical personnel is contaminated by microbial flora during contact with a patient at an average rate of 16 colonies per minute, compared to the rate of three colonies per minute for workers wearing gloves. The contamination increases linearly with the time spent on patient nursing [3]. Hand protection with gloves is essential because skin cleaning/disinfection alone does not remove all pathogens, especially when the contamination is considerable. On the other hand, the medical personnel should always remember that gloves do not protect completely against the transmission

Received: April 27, 2012. Accepted: November 19, 2012.

Corresponding author: A. Garus-Pakowska, Department of Hygiene and Health Promotion, Department of Hygiene and Epidemiology, Medical University of Lodz, 90251 Łódź, Poland (e-mail: anna.garus-pakowska@umed.lodz.pl). 
of microorganisms. Transient bacterial flora can be transmitted through the hands of personnel who used gloves during contact with patients. In addition, some microorganisms, such as hepatitis B or herpes virus, can pass through the microscopic pores formed during normal use of gloves or be transferred when gloves are removed from the hands in a non-aseptic manner [1]. In their study, Pessoa-Silva et al. demonstrated that the use of protective gloves does not protect totally against microbial contamination of hands. A significant increase in the number of bacteria on the hands - despite the use of gloves - was observed especially for such activities as changing diapers in infants and nursing ventilated patients. Therefore, to ensure that the gloves preserve their protective function, appropriate care should be exercised during their handling and use; it is also necessary to remove them from the hands with due care and dispose then immediately after use, thereby reducing the likelihood of cross-transmission of microorganisms [4]. It ought to be noted that wearing protective gloves does not mean that hand washing and/or application of disinfectants is no longer necessary; gloves are used to complement those measures, not instead of them [5].

The guidelines of CDC suggest that:

- Protective gloves should be used in case of contact with blood or other potentially infectious materials, mucous membranes or damaged skin;

- Gloves should be disposed of after contact with a patient; it is unacceptable to use the same pair of gloves upon contact with more than one patient;

- It is necessary to change gloves between dirty and clean procedures performed in the same patient;

- Gloves should not be washed and used upon contact with more than one patient $[1,6]$.

The recommendations of the World Health Organization comprise the following additional items:

- The use of protective gloves does not imply that hand washing and/or application of disinfectants is no longer necessary;
- Gloves should be removed or replaced between contact with the contaminated part of the body and the environment surrounding the patient [7].

In addition, according to WHO, gloves should not be reused. However, if it is not possible to meet this requirement, the safest method of their decontamination should be applied [7].

Pursuant to the Polish instructions, "sterile disposable gloves are recommended for use during procedures performed under aseptic conditions. Disposable non-sterile gloves should be used during all treatments involving contact with blood, body fluids, excretions and secretions, where there is risk of contamination of the worker, while asepsis is not necessary" [8].

The aim of this study was to evaluate the use of protective gloves by medical personnel as recommended by the CDC and WHO.

\section{MATERIALS AND METHODS}

In accordance with the intended research objective, the participants included medium level (nurses) and higher level (doctors) medical staff working at six departments of three hospitals in the province of Łódź. Our study involved all members of the medical personnel of the selected departments: 188 people, including 125 nurses and 63 doctors.

The study was conducted using direct quasi-participant observation. The observation involved continuous accompanying individual members of the medical personnel (nurses, doctors) for several hours and registering all activities performed by them during the observation unit. One hour was selected to serve as the unit of observation. For each employee, a series of random observations was adopted, both during the day and night shifts. During the observation, the following aspects of the use of protective gloves were evaluated:

- use of gloves during contact with blood or other potentially infectious material, 
- use of gloves during contact with mucous membranes and damaged skin,

- use of one pair of gloves for one patient,

- change of gloves between "dirty" and "clean" procedures in the same patient,

- aseptic removal of gloves.

The procedure was assumed to be performed properly when a single pair of gloves was used in each of the circumstances as specified above.

Failure to observe the recommendations was assumed to occur when: (1) gloves were not used at all, or (2) one pair of gloves was used repeatedly, or (3) only one glove was used in the relevant circumstances specified above.

The study protocol was approved by the Research Ethics Committee (Resolution No. RNN/113/06/KE).

Statistical inference was conducted at the significance level $\mathrm{p} \leq 0.05$. Two-sided tests were applied for the verification of statistical hypotheses and a logistic regression model with random effects was used for the analysis of hygiene procedures concerning the use of gloves. In the random effect model, a person was used as a grouping variable. The random effect model was used to account for the within-person correlation.

All statistical analyses were conducted using the R statistical package (http://www.r-project.org).

\section{RESULTS}

The total number of observation units in the course of the study was 1544, during which a total of 3498 activities requiring the use of gloves was reported. The overall level of compliance with the guidelines regarding the use of protective gloves was $50 \%$.

In some departments, gloves were used more often, in other departments they were used significantly less frequently ( $<$ 0.001) (Table 1).

Probably because of frequent contact with blood or other potentially infectious material, the recommendation to
Table 1. Use of protective gloves, depending on the department

\begin{tabular}{lrrrr}
\hline \multirow{2}{*}{ Department } & \multicolumn{4}{c}{ Use of protective gloves } \\
\cline { 2 - 5 } & \multicolumn{3}{c}{ yes } & \multicolumn{3}{c}{ no } \\
\cline { 2 - 6 } & $\mathrm{n}$ & $\%$ & $\mathrm{n}$ & $\%$ \\
\hline Hospital A & & & & \\
$\quad$ surgery department & 425 & 76.6 & 130 & 23.4 \\
$\quad$ medical care department & 532 & 61.8 & 329 & 38.2 \\
Hospital B & & & & \\
$\quad$ surgery department & 233 & 37.6 & 386 & 62.4 \\
$\quad$ medical care department & 46 & 23.8 & 147 & 76.2 \\
Hospital C & & & & \\
$\quad$ surgery department & 161 & 42.4 & 219 & 57.6 \\
$\quad$ medical care department & 352 & 39.6 & 538 & 60.4 \\
\hline p < 0.001. & & & & \\
\hline
\end{tabular}

Table 2. Use of protective gloves depending on the character of the department

\begin{tabular}{lcccc}
\hline \multirow{2}{*}{ Character of the department } & \multicolumn{3}{c}{ Use of protective gloves } \\
\cline { 2 - 5 } & \multicolumn{3}{c}{ yes } & \multicolumn{3}{c}{ no } \\
\cline { 2 - 6 } & $\mathrm{n}$ & $\%$ & $\mathrm{n}$ & $\%$ \\
\hline Medical care & 930 & 47.8 & 1014 & 52.2 \\
Increased risk & 819 & 52.7 & 735 & 47.3 \\
\hline & \\
$\mathrm{n}-$ the number of activities that require wearing gloves. & \\
$\mathrm{p}=0.30$.
\end{tabular}

use protective gloves was respected more frequently in the "increased risk" (surgery) departments. The difference was not statistically significant (Table 2).

The type of performed activity affected the frequency of the use of protective gloves ( $p<0.001)$. The most frequent use was noted for medical procedures (98.6\%), and also wound dressing change ( $81.2 \%$ ) and blood collection (78.3\%). No activity, even such tasks as catheterization, was recorded for which the medical personnel would use gloves in $100 \%$ of cases (Table 3 ).

Our results show that doctors are more likely to use gloves than nurses. The difference is statistically significant at $p<0.001$ (Table 4). Nevertheless, it should be noted that 
Table 3. Use of protective gloves, depending on the type of activity

\begin{tabular}{|c|c|c|c|}
\hline \multirow[b]{2}{*}{ Activity } & \multirow{2}{*}{$\begin{array}{l}\text { Activities that require } \\
\text { wearing gloves } \\
\text { (total) } \\
\text { (n) }\end{array}$} & \multicolumn{2}{|c|}{ Use of protective gloves (\%) } \\
\hline & & yes & no \\
\hline Collect blood & 304 & 78.3 & 21.7 \\
\hline Insert/remove cannula & 144 & 56.9 & 43.1 \\
\hline Insert/remove drip & 1035 & 46.4 & 53.6 \\
\hline Inject & 627 & 51.4 & 48.6 \\
\hline Perform biopsy/endoscopy & 70 & 98.6 & 1.4 \\
\hline Change wound dressing & 239 & 81.2 & 18.8 \\
\hline Insert urinary catheter & 65 & 75.4 & 24.6 \\
\hline Perform per rectum examination/enema & 8 & 62.5 & 37.5 \\
\hline Contact with patient's excrements (change diapers) & 183 & 37.7 & 62.3 \\
\hline Nurse/wash the patient & 576 & 32.1 & 67.9 \\
\hline Feed the patient & 160 & 15.6 & 84.4 \\
\hline
\end{tabular}

$\mathrm{n}-$ the number of activities that require wearing gloves.

$\mathrm{p}<0.001$.

it is nurses who collect blood, give injections, insert catheters and perform many other tasks requiring the use of protective gloves. Accordingly, nurses were found to be more frequently in the circumstances requiring the use of protective gloves than physicians (1622 vs. 127).

Table 4. Use of protective gloves, depending on the profession

\begin{tabular}{lcccc}
\hline \multirow{2}{*}{ Profession } & \multicolumn{4}{c}{ Use of protective gloves } \\
\cline { 2 - 5 } & \multicolumn{3}{c}{ yes } & \multicolumn{3}{c}{ no } \\
\cline { 2 - 5 } & \multicolumn{1}{c}{$\mathrm{n}$} & $\%$ & \multicolumn{1}{c}{$\mathrm{n}$} & $\%$ \\
\hline Doctor & 127 & 88.8 & 16 & 11.2 \\
Nurse & 1622 & 48.3 & 1733 & 51.7 \\
\hline
\end{tabular}

$\mathrm{n}-$ the number of activities that require wearing gloves.

$\mathrm{p}<0.001$.

This conclusion is supported by the following results, since the use of protective gloves depended significantly $(p<0.001)$ on the number of activities that require wearing gloves in the observation unit (the activity index). The more such activities were performed, or the more often the worker had to wear gloves in a unit of time, the less frequently they wore them. The trend of compliance with the requirement to wear protective gloves, depending on the activity index, is shown in Table 5.

Table 5. Use of protective gloves, depending on the activity index

\begin{tabular}{lccccc}
\hline & \multicolumn{4}{c}{ Use of protective gloves } \\
\cline { 2 - 6 } Activity index* & \multicolumn{3}{c}{ yes } & & no \\
\cline { 2 - 6 } & $\mathrm{n}$ & $\%$ & $\mathrm{n}$ & $\%$ \\
\hline $1-3$ & 774 & 57.2 & 580 & 42.8 \\
$4-6$ & 584 & 49.4 & 597 & 50.6 \\
$>6$ & 391 & 40.6 & 572 & 59.4 \\
\hline & & & & \\
$*$ & The number of activities that require wearing gloves per observa- \\
tion unit. \\
$\mathrm{n}-$ the number of activities that require wearing gloves. \\
$\mathrm{p}<0.001$.
\end{tabular}

Similarly, the effective workload (the total working time in an observation unit) affects the degree of compliance with the recommendation concerning the wearing of protective 
gloves. The more the workers were heavily burdened with work, the less frequently they complied with the recommendation to wear protective gloves (Table 6).

Table 6. Use of protective gloves, depending on the index of effective workload

\begin{tabular}{lrrrr}
\hline \multirow{2}{*}{$\begin{array}{l}\text { Index of effective workload } \\
(\text { min })^{*}\end{array}$} & \multicolumn{3}{c}{ Use of protective gloves } \\
\cline { 2 - 5 } & \multicolumn{2}{c}{ yes } & \multicolumn{3}{c}{ no } \\
\cline { 2 - 5 } & \multicolumn{1}{c}{$\mathrm{n}$} & $\%$ & \multicolumn{1}{c}{$\mathrm{n}$} & $\%$ \\
\hline $1-15$ & 293 & 53.1 & 259 & 46.9 \\
$16-45$ & 1034 & 49.5 & 1053 & 50.5 \\
$\geq 46$ & 422 & 49.1 & 437 & 50.9 \\
\hline
\end{tabular}

* The total working time in an observation unit.

$\mathrm{n}-$ the number of activities that require wearing gloves. $\mathrm{p}=0.051$.

It was also found that gloves were used more often during the morning shift, with a similar structure of activities occurring throughout the day, but the association was on the border of statistical significance, $\mathrm{p}=0.12$ (Table 7).

Table 7. Use of protective gloves, depending on the time of the day

\begin{tabular}{lrccc}
\hline & \multicolumn{3}{c}{ Use of protective gloves } \\
\cline { 2 - 5 } \multicolumn{1}{c}{ Time of day } & \multicolumn{2}{c}{ yes } & \multicolumn{2}{c}{ no } \\
\cline { 2 - 5 } & 1059 & 55.1 & 864 & 44.9 \\
\hline $7-12$ a.m. & 311 & 42.3 & 425 & 57.7 \\
1-6 p.m. & 379 & 45.2 & 460 & 54.8 \\
7-11 p.m. & & & & \\
\hline
\end{tabular}

$\mathrm{n}$ - the number of activities that require wearing gloves. $\mathrm{p}=0.12$.

The collaboration with the hospital Infection Control Teams affected the use of protective gloves. The better the assessment expressed by the team of the department personnel, the more frequently the personnel complied with the recommendation to use protective gloves when it was necessary $(\mathrm{p}<0.001)$.
The aseptic removal of gloves also plays a role in minimizing the spread of germs around the hospital environment. Among nurses, the scope of proper conduct amounted to only from $15 \%$ to $48.6 \%$. Better results were observed in the group of physicians (mean $77.6 \%$ ).

Considering that hands were washed more frequently after contact with patients than before such contact $[9,10]$, it once again becomes evident that hand hygiene, as an element of protection against infection, is regarded by the medical personnel as being more for their own protection than for the safety of the patients. The observed multiple use of disposable gloves evidently confirms that attitude. In the group of physicians, such situations were not recorded. If the doctor wore gloves, they were always changed when dealing with another patient. Unfortunately, nurses were observed to be using a single pair of gloves upon contact with a number of consecutive patients. In 3355 activities in which nurses were required to use protective gloves, the glove-wearing procedure (as described above) was performed in 1622 cases. Out of the remaining cases classified in this study as a failure to observe the procedure, in as much as 718 cases, the nurses did not change gloves between the contact with consecutive patients.

\section{DISCUSSION}

In accordance with the recommendations, the use of protective gloves is required in case of contact with blood, mucous membranes, or other potentially infectious material. Gloves should always be changed when shifting from dirty to clean procedures on the same patient. It is unacceptable to use the same pair of gloves for contact with more than one patient [1]. In 2001, in Birmingham, it was shown that the use of protective gloves during blood collection was very important or important for $98.6 \%$ of nurses and $82.7 \%$ of physicians. However, only $79.7 \%$ of nurses and $28 \%$ of doctors reported using disposable gloves always or almost always during blood collection. At the same time, $5.6 \%$ of 
nurses and $32 \%$ of doctors reported that during this procedure, they never or almost never wore gloves [11]. Observation-based studies revealed that the recommendation to use protective gloves was followed at the level of 58.8\% [12]. The analysis of the results of our study showed that the overall level of compliance with the recommendation to use protective gloves in the circumstances that in accordance with the guidelines so require was 50\%. Probably due to frequent contact with blood and/or other potentially infectious materials, the compliance with the recommendation to use protective gloves was higher in the "increased risk" departments. The nature of the activities also affects the frequency of the use of protective use $(p<0.001)$. Most frequently, gloves were worn to perform medical procedures (98.6\%), and also to change wound dressings $(81.2 \%)$ and collect blood (78.3\%). No activity was recorded for which the medical personnel would use the gloves in $100 \%$ of the "must use gloves" cases (this refers even to such procedures as catheterization). The authors of a study conducted in the city hospital in Ireland on a group of 73 medical workers also reported an increased rate of the use of protective gloves in case of invasive medical procedures. These results may suggest greater concern of medical personnel for their health in the case of procedures involving tissue breakage [13].

In our study, protective gloves were used more frequently by doctors. Perhaps this is due to the smaller number of the observed circumstances in which physicians were required to wear protective gloves, compared to nurses. This conjecture may be confirmed or rejected by the results of univariate analysis implemented to test the association between the use of protective gloves and varying workload. An inverse relationship was noted between the number of circumstances requiring the use of gloves per observation unit and the level of compliance with that requirement. The level of complyiance with the requirement to use suitable hygiene procedures can be improved by more strict supervision exercised by the head of the hospital department, ward nurses and the Infection Control Teams. The latter conjecture is confirmed by the lower frequency of the use of protective gloves noted during night duty hours, when the supervisory personnel was usually absent.

The aseptic removal of gloves also plays a significant role in minimizing the spread of germs within the hospital environment. No similar analysis could be located in the accessible literature. The present study demonstrates that medical personnel are moderately trained to follow correct habits regarding the safe removal of gloves. Among the nurses, proper procedures were applied in $28.5 \%$ of cases. Better results were noted in the group of physicians (mean 77.6\%).

A serious problem is the repeated use of the same gloves for contact with a number of consecutive patients. This augments the wrong practice in ensuring protection against infections - the protection of only the worker, but not the patient. Excessive workload certainly contributed to the multiple use of disposable gloves or failure to use gloves at all. The insufficient financing of the hospitals suggested by the media did not seem to play a role in that particular respect. The examined workers of the hospitals confirmed sufficient availability of the individual protection equipment. However, they highlight the poor quality of the gloves and cases of dermal irritation and allergy associated with their use. The managerial staff of the health care units should pay particular attention not only to the sufficient availability of the individual protection equipment, but also to its quality.

\section{CONCLUSIONS}

The use of disposable protective gloves by health workers is inadequate. Continuous training/retraining of medical personnel regarding the proper use of gloves and their aseptic removal is an urgent necessity; it is also necessary to remind them that protective gloves belong to the category of disposable equipment and must not be reused. 


\section{REFERENCES}

1. Boyce J, Pittet D. Guideline for hand hygiene in healthcare settings: Recommendations of the Healthcare Infection Control Practices Advisory Committee and the HICPAC/SHEA/APIC/IDSA Hand Hygiene Task Force. Am J Infect Control 2002;30:S1-6.

2. Allen G. Hand hygiene, an essential process in the OR. AORN J 2005;82(4):561-2.

3. Pittet D, Dharan S, Touveneau S, Sauvan V, Perneger TV. Bacterial contamination of the hands of hospital staff during routine patient care. Arch Intern Med 1999;159(8):821-6. DOI: 10.1001/archinte.159.8.821

4. Pessoa-Silva C, Dharan S, Hugonnet S, Touveneau S, PosfayBarbe K, Pfister R, et al. Dynamics of bacterial hand contamination during routine neonatal care. Infect Control Hosp Epidemiol 2004;25(3):192-7. DOI: 10.1086/502376.

5. Marcinkowski JT. Hygiene, preventive and organization in the medical professions. Warszawa: Wydawnictwo Lekarskie PZWL; 2003. p. 115-28 [in Polish].

6. Pittet D, Boyce J. Revolutionising hand hygiene in health-care settings: guidelines revisited. Lancet Infect Dis 2003;3:269-70.

7. Pittet D, Allegranzi B, Boyce J. The World Health Organization Guidelines on Hand Hygiene in Health Care and Their consensus recommendations. Infect Control Hosp Epidemiol 2009;30(7):611-22. DOI: 10.1086/600379.
8. Staszkiewicz W, Hryniewicz W, Grzesiowski P, Ozorowski T. Practical rules for hospital infection control. Set of recommendations and procedures for Polish hospitals. Warszawa: Główny Inspektor Sanitarny; 2000 [in Polish].

9. Garus-Pakowska A, Sobala W, Szatko F. Observance of hand washing procedures performed by the medical personnel before the patient contact. Part I. Int J Occup Med Environ Health 2013;26(1):113-21. DOI: 10.2478/s13382-013-0092-4.

10. Garus-Pakowska A, Sobala W, Szatko F. Observance of hand washing procedures performed by the medical personnel after the patient contact. Part II. Int J Occup Med Environ Health 2013;26(2) [in print]. DOI 10.2478/s13382-0130094-2.

11. Stein A, Makarawo T, Ahmad M. A survey of doctors' and nurses' knowledge, attitudes and compliance with infection control guidelines in Birmingham teaching hospitals. J Hosp Infect 2003;54:68-73.

12. Kuzu N, Özer F, Aydemir S, Yalcin AN, Zencir M. Compliance with hand hygiene and glove use in a university-affiliated hospital. Infect Control Hosp Epidemiol 2005;26(3):312-5. DOI: $10.1086 / 502545$.

13. Creedon S. Healthcare workers' hand decontamination practices: compliance with recommended guidelines. J Adv Nurs 2005;51:208-16.

This work is available in Open Access model and licensed under a Creative Commons Attribution-NonCommercial 3.0 Poland License - http://creativecommons.org/ licenses/by-nc/3.0/pl/deed.en. 